9 Kaestner F, Mostert C, Behnken A, Boeckermann I, Ternes F, Diedrich M, et al. Therapeutic strategies for catatonia in paraneoplastic encephalitis. World J Biol Psychiatry 2008; 9: 236-40.

10 Bhati MT, Datto CJ, O'Reardon JP. Clinical manifestations, diagnosis, and empirical treatments for catatonia. Psychiatry (Edgmont) 2007; 4: 46-52.

11 Rohland BM, Carroll BT, Jacoby RG. ECT in the treatment of the catatonic syndrome. J Affect Disord 1993; 29: 255-61.

12 Malur C, Pasol E, Francis A. ECT for prolonged catatonia. J ECT 2001; 17 55-9.

13 Maletzky BM. The first-line use of electroconvulsive therapy in major affective disorders. J ECT 2004; 20: 112-7.

14 Fink M. Catatonia and ECT: Meduna's biological antagonism hypothesis reconsidered. World J Biol Psychiatry 2002; 3: 105-8.

15 White $\mathrm{DA}$, Robins $\mathrm{AH}$. Catatonia: harbinger of the neuroleptic malignant syndrome. Br J Psychiatry 1991; 158: 419-21.

16 Lee JW. Serum iron in catatonia and neuroleptic malignant syndrome. Biol Psychiatry 1998; 44: 499-507.

17 Fink M, Taylor MA. Neuroleptic malignant syndrome is malignant catatonia, warranting treatments efficacious for catatonia. Prog Neuropsychopharmacol Biol Psychiatry 2006; 30: 1182-3.

18 Hung YY, Yang PS, Huang TL. Clozapine in schizophrenia patients with recurrent catatonia: report of two cases. Psychiatry Clin Neurosci 2006; 60: $256-8$.
19 Guzman CS, Myung VH, Wang YP. Treatment of periodic catatonia with olanzapine: a case report. Rev Bras Psiquiatr 2007; 29: 380.

20 Hervey WM, Stewart JT, Catalano G. Treatment of catatonia with amantadine. Clin Neuropharmacol 2012; 35: 86-7.

21 Rosebush PI, Hildebrand AM, Furlong BG, Mazurek MF. Catatonic syndrome in a general psychiatric inpatient population: frequency, clinical presentation, and response to lorazepam. J Clin Psychiatry 1990; 51: 357-62.

22 Deafness Research UK. Deafness - The Facts. Deafness Research UK, 2009 (http://www.deafnessresearch.org.uk/factsheets/deafness-thefacts. pdf).

23 British-sign.co.uk. What is British Sign Language? British-sign.co.uk, 2012 (http://www.british-sign.co.uk/what_is_british_sign_language.php).

24 ten Have M, Vollebergh W, Bijl R, Nolen WA. Bipolar disorder in the general population in The Netherlands (prevalence, consequences and care utilisation): results from The Netherlands Mental Health Survey and Incidence Study (NEMESIS). J Affect Disord 2002; 68: 203-13.

25 De Zelicourt M, Dardennes R, Verdoux H, Gandhi G, Khoshnood B Chomette $\mathrm{E}$, et al. Frequency of hospitalisations and inpatient care costs of manic episodes: in patients with bipolar I disorder in France. Pharmacoeconomics 2003; 21: 1080-90.

26 Taylor MA, Abrams R. Catatonia: prevalence and importance in the manic phase of manic-depressive illness. Arch Gen Psychiatry 1977; 34 1223-5.

\title{
Enhancing the effectiveness of community drug and alcohol teams working with opioid-dependent pregnant women: results of an audit
}

\author{
Mani Sairam, ${ }^{1}$ Rakesh Magon, ${ }^{2}$ Christos Kouimtsidis ${ }^{3}$
}

The Psychiatrist (2012), 36, 421-423, doi: 10.1192/pb.bp.111.038166

${ }^{1}$ Beech Low Security Forensic Rehabilitation Unit, Kingsley Green Hospital; ${ }^{2}$ Oxford House Community Mental Health Team, Bishops Stortford; ${ }^{3}$ Hertfordshire Partnership NHS Foundation Trust, St Albans

\section{Correspondence to Christos}

Kouimtsidis

(drckouimtsidis@hotmail.com)

First received 5 Dec 2011, final revision 3 Feb 2012, accepted 9 May 2012
Aims and method To evaluate the quality of services offered by community drug and alcohol teams (CDATs) to pregnant women in substitution treatment. A full audit of the practice across all local CDATs against national standards was undertaken in 2008 and 2010.

Results Quality of services improved and met three standards in 100\% and the fourth standard in $96 \%$ of cases. There was good implementation of the recommendations arising out of the action plan of the first cycle, which resulted in significant improvements in interagency liaison and risk-benefit analysis documentation within the CDATs.

Clinical implications Management of pregnant women in substitution treatment can be improved by adhering to a multipronged approach as identified by this audit.

Declaration of interest All authors were members of the Addiction Services in Hertfordshire when this audit took place.
The extent of problem drinking and drug use in pregnancy is difficult to estimate accurately owing to associated stigma and secrecy, and it is probably underestimated. A quarter of those presenting to drug misuse agencies are women of childbearing age. ${ }^{1}$ A national household survey in the USA on drug use and health (2007-2008) showed $5.1 \%$ of pregnant women using illicit drugs in the past month (including cocaine). ${ }^{2}$ The recent confidential enquiry into maternal deaths highlighted drug- and/or alcohol-related deaths in this population. ${ }^{3}$ Substance misuse was directly or indirectly related to death in 57 out of 295 reported deaths (12 alcohol dependent; 45 illicit drugs dependent). The 
report concluded that more women were dying from direct/ indirect consequence of substance misuse than other psychiatric causes. The majority died from the physical consequences of misuse rather than overdose or suicide. The majority of them did not receive care from integrated drug addiction services or were poorly managed, with significant interagency communication failures. ${ }^{3}$ Studies looking at the care received by pregnant drug users have highlighted: ineffective interagency working and the importance of effective liaison between professionals in different agencies; ${ }^{4,5}$ sharing of experience; and training between organisations. ${ }^{6}$

The aim of the audit was to compare local practice within substitution treatment services against the following national standards: (a) treatment aim is to achieve stability; (b) detoxification should be offered when it is client's choice and should take place in the second trimester; (c) evidence of good interagency liaison; and (d) discussion and documentation of risk-benefit analysis in the client's notes. ${ }^{7}$

\section{Method}

A retrospective case-note review was conducted of all female clients referred or attending community drug and alcohol teams (CDATs) in Hertfordshire in the calendar year 2008 (from 1 January 2008 to 31 December 2008). Pregnant women were identified by professionals within each CDAT. Notes (hard copies and electronic notes) were assessed. Data were collected on a data-collection form to capture the characteristics of the sample and compare local practice with the above agreed standards. Descriptive statistics were used to analyse results. The results of the first cycle generated recommendations to enhance service delivery. The second cycle of the audit was conducted retrospectively for the calendar year 2010. In the second cycle, quality of services and the implementation of the recommendations generated following the first cycle were examined.

\section{Results}

During the first cycle, 21 women were identified. All but 1 used opioids, either alone (6 women) or with other drugs (14 women) and they were on substitute prescribing. One woman used only benzodiazepines. Methadone was prescribed to the majority of women $(n=17)$. One woman dropped out of treatment. New clients presented to CDAT late in pregnancy (average of 21.6 weeks), whereas for existing clients pregnancy was confirmed at an average of 11 weeks.

All treatment plans were agreed with the woman and reflected her choice. The treatment aim for 12 women was detoxification and for 8 it was stability (first standard). All detoxifications had taken place during the second trimester (second standard). Liaison with other services (general practitioner and midwife/antenatal services) has been documented in 19 cases (90\%, third standard). Documentation of risk-benefit analysis existed in 14 cases (67\%, fourth standard). The significant gaps in the interagency liaison and risk-benefit analysis have generated six recommendations, which were agreed in clinical governance and were implemented in all CDATs (Table 1).
During the second audit cycle, 25 women were identified. Demographic details and comparison between the two samples are presented in Table 2. In contrast with the sample in the first cycle, only two women were new to the services. Treatment preference for stability or detoxification, time of detoxification and liaison with other services met national standards in all cases. Documentation of risk-benefit analysis has improved from $67 \%$ to $96 \%$ (present in all but one woman's notes).

The extent of adherence to our recommendations was variable. Four recommendations were implemented in $90 \%$ and above. Obtaining consent for liaison with other services was implemented only in $68 \%$, although liaison has taken place in all cases. The required assertive management was reflected in $84 \%$ of care plans (Table 1).

\section{Discussion}

Overall there was good adherence with the recommendations arising out of the action plan of the first cycle. A possible explanation for not having consent to liaise with other

Table 1 Implementation of recommendations in the second cycle $(n=25)^{\mathrm{a}}$

\begin{tabular}{lr} 
Recommendations & $n(\%)$ \\
\hline Obtaining consent to liaise with other services & $17(68)$ \\
\hline $\begin{array}{l}\text { Contact established by keyworker with other } \\
\text { services }\end{array}$ & $25(100)$ \\
\hline $\begin{array}{l}\text { Assertive management in pregnancy reflected in } \\
\text { care plan }\end{array}$ & $21(84)$ \\
\hline $\begin{array}{l}\text { Identification within each CDAT of a specialist team } \\
\text { member }\end{array}$ & $25(100)$ \\
\hline $\begin{array}{l}\text { Provision of information leaflets/posters to women } \\
\text { of childbearing age }\end{array}$ & $25(100)$ \\
\hline At least one medical review during pregnancy & $23(92)$
\end{tabular}

a. Number of pregnant women attending community drug and alcohol team (CDAT) services in Hertfordshire Partnership NHS Foundation Trust between January 2010 and December 2010.

Table 2 Comparison of the characteristics of the participants in the first and second cycle

\begin{tabular}{lcc} 
& \multicolumn{2}{c}{$n(\%)$} \\
\cline { 2 - 3 } & $\begin{array}{c}\text { First cycle } \\
2008 \\
(n=21)\end{array}$ & $\begin{array}{c}\text { Second cycle } \\
2010 \\
(n=25)\end{array}$ \\
\hline New service users & $11(52)$ & $2(8)$ \\
\hline White British & $21(100)$ & $23(92)$ \\
\hline Accommodation problems & $12(57)$ & $5(20)$ \\
\hline Unemployed & $19(90)$ & $24(96)$ \\
\hline Previous pregnancies & $16(76)$ & $22(88)$ \\
\hline Married or in a relationship & $14(67)$ & $18(72)$ \\
\hline Drug use in partner & $8(57)^{\mathrm{a}}$ & $10(56)^{\mathrm{c}}$ \\
\hline Looked-after children & $11(69)^{\mathrm{b}}$ & $10(45)^{\mathrm{d}}$ \\
\hline
\end{tabular}

a. Total $n=14$ for this variable.

b. Total $n=16$ for this variable.

Total $n=18$ for this variable.

d. Total $n=22$ for this variable. 
services could be explained by a verbal consent being obtained but not documented in a separate consent form. Most care plans (84\%) had detailed plans to appropriately manage the client during the pregnancy. In the rest, generic plans not specific to pregnancy were found. This reflects a failure to update existing care plans, which might be a cause for concern and relevant improvement. Two women did not have a medical review at CDAT during their pregnancy, one of whom was offered appointments with the CDAT doctor but did not attend these appointments.

All the teams had identified a team member who was involved in the management of pregnant service users and who was the key liaison member for their respective teams. This has helped maintain a good relationship with other services. This member of staff had the responsibility of attending monthly liaison meetings with Social Services and maternity services to discuss this client group. Leaflets about illicit drug use, effects on menstruation, pregnancy and substitute prescription can improve education among this group. It might be a good idea for all women of childbearing age who are on substitute prescription to be given a leaflet by their keyworkers irrespective of pregnancy status. The above two recommendations might help in the early identification of pregnancy in existing CDAT clients and earlier access to substitution services for new clients.

There are several biopsychosocial factors that affect the course of a pregnancy and it is sometimes easy to forget that drug use is only one of them. It is also easy to assume that drug use by itself would make a woman incapable of caring for a baby, which is an incorrect assumption. The basic principles underlying good treatment of substance misuse problems in general apply to pregnant women, with special emphasis on the health of the unborn child. However, it should be emphasised that treatment guidelines are just guidelines and they provide a framework of good and evidence-based practice that needs to be adapted to the particular needs of each individual. Therefore, diversion from guidelines might be justifiable but this should be well supported and documented. It is difficult to measure the specific effect of the above recommendations on the improved quality of the services observed. We hope though that other service providers might find them relevant and helpful to ensure the delivery of high-quality care to a client group who are vulnerable and have complex needs.

\section{About the authors}

Mani Sairam is a specialist registrar at Beech Low Security Forensic Rehabilitation Unit, Kingsley Green Hospital (Hertfordshire Partnership NHS Foundation Trust) and at the time of the audit worked at the Addicition Services in the Trust. Rakesh Magon is a consultant psychiatrist in the Oxford House Community Mental Health Team, Bishops Stortford (Hertfordshire Partnership NHS Foundation Trust) and at the time of the audit worked at the Addicition Services in the Trust. Christos Kouimtsidis, is the lead consultant psychiatrist in the Addiction Services, Hertfordshire Partnership NHS Foundation Trust.

\section{References}

1 Department of Health. Statistics from the Regional Drug Misuse Databases for Six Months ending March 1999 (Bulletin 1999/33). Department of Health, 1999.

2 Substance Abuse and Mental Health Services Administration. Results from the 2008 National Survey on Drug Use and Health: National Findings. NSDUH Series H-36, HHS Publication No. SMA 09-4434. Office of Applied Studies, US Department of Health and Human Services, 2009.

3 Lewis G. The Confidential Enquiry into Maternal and Child Health (CEMACH). Saving Mothers' Lives: Reviewing Maternal Deaths to Make Motherhood Safer - 2003-2005. The Seventh Report of the Confidential Enquiries into Maternal Deaths in the United Kingdom. CEMACH, 2007.

4 Klee, H. Drug-using parents: analysing the stereotypes. Int J Drug Policy 1998; 9: 437-48.

5 Brent, Kensington, Chelsea and Westminster Substance Misuse Service. Children of Substance Misusers: A Mapping Exercise for Children of Substance Misusers. Carried out within the Substance Misuse Services in the London Boroughs of Kensington and Chelsea, Westminster, Hammersmith and Fulham, and Ealing. Brent, Kensington, Chelsea and Westminster Substance Misuse Service, 2001.

6 Morrison C, Siney C. Maternity services for drug misusers in England and Wales: a national survey. Health Trends 1995; 27: 15-7.

7 Department of Health. 7.4 Pregnancy and neonatal care. In Drug Misuse and Dependence - UK Guidelines on Clinical Management: 80-83. Department of Health, 2007 